\title{
Cont $770318-35$
}

A COLD-BORE VACUUM SYSTEM DESIGN FOR POPAE

Y. Cho, T. K. Khoe, J. Moenich, L. G. Ratner

Prepared for

Particle Accelerator Conference

Chicago, Illino is

March 16-18, 1977

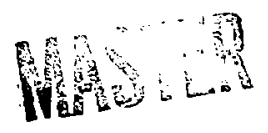

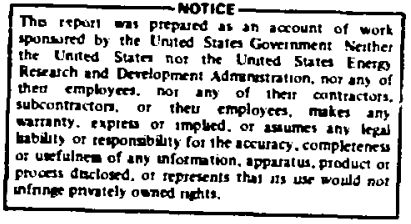

sponeured by the theu employer.

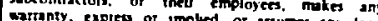
babily ot tepponsability fot the socuracy. completenes infrnes parvicly ooned restes.
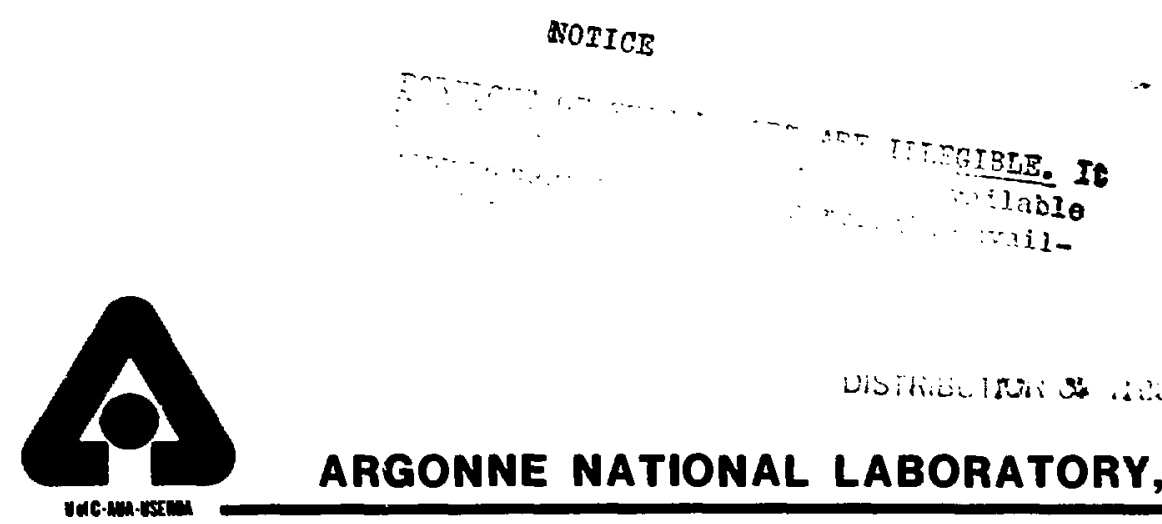

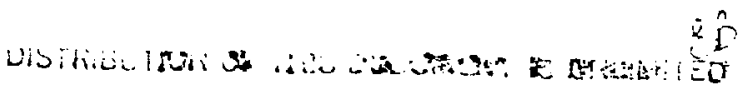

ARGONNE NATIONAL LABORATORY, ARGONNE, ILLINOIS

operated under contract $W-31-109-E n g-38$ for the U. S. ENERGY RESEARCH AND DEVELOPMENT ADMINISTRATION 
The facilites of Argonne National Labotatury are whed by the Linted states Gurern-

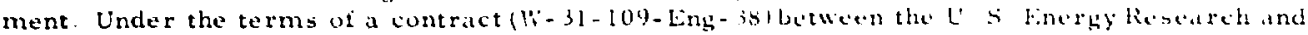

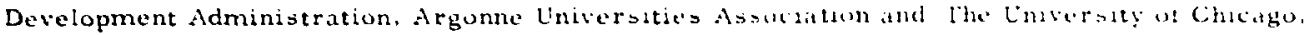
the University employs the stafi and operates the Liboratory an acordine 6 ith policies and programs iormulated, approved and reviewed by the Associdtion

\section{MEMBE:AS OF MRGONNE L'NIVRSIIES ASSOCIAIION}

The University of Arizond Carnegie- Mellon University Case Western Reserve Unuersity The University oi Chicago University ot Cincinnati Illinois Institute of Technology University of Illunois Indiana University Iowa State University The University of fowa
Kansas State Unueresty The Linversity of kiansas Luyula Cnuversity Marquette Lnisersity Machadn State Limersis The Linversity ot Machigan Unwersity of Minmesota Unaversty uf Missuer Northwestern Vinersty University of Wotre Dame
The Ohwa State Enmersty

Ohun Lnuversity

The Pertusyluma Side Lnuersaty

purduc liniversity

Sant lous Untiersity

Southern lllumis lnuversity

The University of rexis at Austin

Washington University

Wayne Siate University

The University of Wisconsin

\section{NOTICE}

This report was prepared as an account of werk sponsored by the United States Government. Neither the United States nor the United States Energy Resea rch and Development Administration, nor any of their employees, nor any oi their contractors, subcontractors, or their employecs, makes any warranty, express or implied, or assumes any legal liability or responsibility for the accuracy, completeness or usefulness of any information, apparatus, product or process disclosed, or represents that its use would not infringe privately-owned rights. Mention of commercial products, their manufacturers, or their suppliers in this publication does not imply or connote approval or disapproval of the product by Argonne National Laboratory or the U. S. Energy Research and Development Administration. 


\section{Abstract}

We have made a conceptual design of a cold-bore vacuum system for the Fermilab $1000 \mathrm{GeV} \times 1000 \mathrm{GeV}$ colliding heam facility (POPAE). A double wall vacuum system is used between magnets and cryopumped molecular traps between the cold-bore and warm straight section regions. The bean-induced pressure $r$ ise phenomena has been taken into accounc as well as the liquid helium leak rate between the cold magnets and the vacuum bore. since beam for POPAE will be injected at the desired energy, there are no heat loads from accelerated beam or eddy currents and the cold-bore system appears very attractive. This design is based on the best exper imental evidence available today.

\section{Introduct ion}

It is natural to consider a cold-bore vacuum system for storage $r$ ings constructed with superconducting magnets. The cont inuously-distr ibuted cryopuming may result in reduced aperture requirements, an improved packing factor in the machine lattice, and lower costs than a conventional vacuun system. Since bean for POPAE will be injected at the desired energy, there is no need for acceleration, so there are no heat loads from the accelerated bunched beam or from eddy currents, and the cold-bore system is very attractive.

The vacuum requirements of proton storage $r$ ings are determined primarily by the need to (a) avoid the bean-induced pressure rise otsiserved at the CEF ISR, (b) clear trappod electrons and numat ive inns, and (c) provide low enough pressure so that hackijroinds f rom beam-yas interactions can bre tolerated by the exper inents.

To meet these requirements, the presently designed system will use 6-cm ID aluminum vacuum chambers, operating at $4.5^{\circ} \mathrm{K}$ in the curved sections and at room temper ature in the long sfraight sections. There will be a pressure of $10^{-11}$ Torr in the interaction regions, while the cold-bore pressure will be $\lesssim 10^{-13}$ Torr and may drop even further as residual gas molecules condense on the surface. The entire residual gas load forms only a very small fraction of a monolayer even if completely absorbed. It should also be noted that the outgassing rate at $4.5 \%$ is essentially zero. A cryopumped transition region between the warm and cold areas will reduce molecular transmission by a factor of about 200 . All connections in the lattice region will be welded and flanges will be used only in the warm sections of the rings.

The design of the present system is based on the best exper inental evidence available today and appears to be an attractive solution. Sinilar cold-bore vaculm systems are planned for both the Fermilab Energy Doubler/Saver and for the Lawrence Berkeley Laboratory ESCAR project. While neither of these mach ines presents vacuum requirements as strinyent as those of POPAE, the research and develoginent progran at ESCAR has been useful in the design of the coldbore vacuum systen for POPAE. However, further

Work supported by the v. S. Energy Research and Develogent Aoministration. exper imental work will be undertaken to test these concepts with components designed specifically for POPAE.

\section{Bean-Gas Background}

In coll iding-beam experiments, background events can come from the circulating beam interacting with the residual gas in the vacuum and/or from txearl particles striking the walls. The latter can by: controlled by collimation and scraping. To maintain a sufficiently lov beam-gas background, it is mecessary to reduce the density of residual gas molecules by several orders of magnitude from that of a conventional accelerator. The vacum system is designed to produce a vacuum of $10^{-11}$ Torr in the interastion regions, a value typical of the ISR. A $5 \mathrm{~A}$ circulating current will yield about $10^{4}$ interactions/s in $100 \mathrm{~m}$ of $10^{-11}$ Torr, compared with $10^{8}$ bean-beam events for a luninosity of $10^{33} \mathrm{~cm}^{-2} \mathrm{~s}^{-1}$. Since this background is easily measured by running one beam at a $t$ ime, it will not be troublesame even at much lower luminosity.

\section{Bean Neutral ization}

Electrons and negative ions produced by ionization of the residual gas becone trapped in a potential well created by the coulomb field of the proton bean. The trapped ions provoke an electronproton transverse instability and also partially neutralize the bean, shifting the betatron turn of the circulating protons. To eliminate tress affret:s, is seni-oyl indr ical clear ing electroxs of apy roxilwitoly the sam: diameter as the beam pign: and li, ent |rarl i:: plaked between every magnet. This: mlett reak will

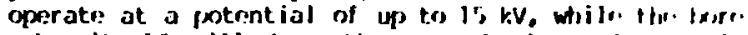
tube itself will form the ground electrex:. Ithi:; potential is sufficient to keep the tume shill. (1) $\leqslant 10^{-3}$.

\section{Surface Treatment and Bake-out}

of major importance is the proper processing of materials which go into the vacuum system. Exper imental results $s^{2}, 3$ show that the following steps lead to acceptable outgassing rates:

1) Chemically pol ish all materials

2) Bake to $150^{\circ} \mathrm{C}$ in a vacuum furnace at $10^{-6}$ Torr

3) Glow discharge in argon and oxygen

4) Bake-out after assembly at $150^{\circ}$

In situ bake-out will be accomplished by flowing hot gas through the magnets.

This treatwent is expected to result in an cutgassing fate at room temperature of $4 \times 10^{-1}$ Torr - $1 \mathrm{~cm}^{-2} \mathrm{~s}^{-1}$ with a residual gas composition of 998 hydrogen. As the curved-lattice section is cooled to $4.5 \%$, the outgassing rate in the cold-bore section goes essentially to zero.

\section{i Surface Phenomena}

There have been numerous arguments for and against cold bore. 6 one of these is related in, the bea-induced pressure $r$ ise, or "pressure bump phenomenon" observed at the CER ISR. This effect is caused by residual gas ions being accelerated into the 


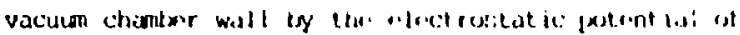
the stored bean. Thisi liberates adsorted molicules and raises the chanber pressure, which in turn results in more ions being generated. At a critical current, $I_{\text {crit }}$ the effect runs away and leads to a local pressure bump which destroys the bean.

For the gecmetry of POPAE with a $\%$ ld-bore vacuum system, the Fischer equation predicts 7,8

$$
\pi I_{\text {crit }}=8 \times 10^{4} \mathrm{~A} \text {. }
$$

The desorption coeff icient $T$. (number of atoms released per incident ion) depends on the mass and energy of the ionized residual gas atoms, as well as the surface conditions. In POPAE, the only imporiant residual gas is expected to be hydrogen, and the bearm-to-wall potential will be approximately $500 \mathrm{~V}$, so the banbarding ions will be $\sim 0.5 \mathrm{keV}$ protons.

Erents and McCracken ${ }^{9}$ have stuxiled the desorption of various gases condensed on a coppper surface at 1 iquid-helium temperature. Using 5 and $20 \mathrm{keV}$ protons, they showed that the desorption coefficient is independent of the thickness of surface coverage if the coverage is thicker than one monolayer $(\sim 3 x$ $10^{15}$ molecules $\left(\mathrm{cm}^{2}\right)$, but decreases with thinner coverage. This trend was true for all gases studied. Fo: hydrogen, which has the largest yield, they found that for a thickness of a few monolayers $n \sim 5 \times 10^{4}$ atoms/ion, while for coverage of one-tenth of a monolayer, $\pi \approx 400$ to 2000 atoms/ion, depending on the experimental conditions.

The authors have interpreted their results in terms of a thermal-spike model, although the model could not explain all aspects of the experimental results. According to the thermal-spike model, the incident proton will go through the thin layer of hydrogen, and most of its energy will be deposited in the metal substrate, generating a thermal spike in the substrate. From the energy-range relation and the range straggling of protons of a tew kev in copper, one can calculate the radius of the tinermal spike. The energy of the incident proton will be given partly to the lattice of the substrate and partly to the orbital electrons. Because the mean free path for electrons at these temperatures is very long, the energy transferred to the electrons will be dissipated over a large volume and only give a small temperature $r$ ise. Therefore, the model considers only energy given directly to the lattice by the incident proton.

For POPAE, with $0.5 \mathrm{keV}$ protons on an aluminum substrate, the energy transferred to the lattice is $200 \mathrm{eV}$ and the spike radius is $200 \mathrm{~A}$, compared with $420 \mathrm{eV}$ and $210 \mathrm{~A}$ for Erents and McCracken's exper iment of $5 \mathrm{keV}$ on copper. This suggests a factor of two less yield than for $5 \mathrm{keV}$ protons on copper, iा 200 to 1000 for 0.1 monolayer of hydrogen

The expected coverage of adsorbed molecules on the cold sections of the POPAE vacuun chanber is a very small fraction $\left(\sim 10^{-6}\right)$ of a monolayer. Even taking a very pessimist ic set of values 10.1 monolayer of hydrogen and Mccracken's larger value for $\eta$ without the factor-of-two improvement from lower ion energy) gives:

$$
I_{\text {crit }}=40 \mathrm{~A} \text {. }
$$

The true value will likely be considerably larger, and this effect should be neg?.igible in the cold bore.

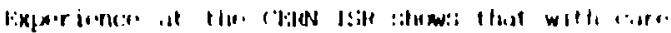

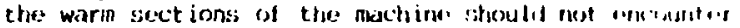
pressure-bunp problems for beans of up to a liw tori: of amperes. In the transition section between warm and cold sections, where one expecis high concentrations of condensed residual gas, the cryosorbing surface will be hidden behind baffles, and the beam-induced ions will not reach the condensed gas.

There has been some speculation that water vapor frozen on the chamber surface may release byorogen molecules when bambarded by ions. ${ }^{6}$ A study of hydrogen released from frozen water and hydrocarixuns by ion bombardment shows the yield will be nreglingitso in POPAF. As an example, we have consiowerced a pessimistic case in which the surface is coverral with, a monolayer of ice. Ghormley and Stewart ${ }^{l 6}$ havis lound that the number of hydrogen molecules releasod par $100 \mathrm{eV}$ of energy deposited in ice is $\mathrm{G}=0.1$. Usiny this value and $\mathrm{a} d \mathrm{dE} / \mathrm{dx}$ for $0.5 \mathrm{keV}$ protons in water of $0.5 \mathrm{eV} / \mathrm{A}$, the expected hydrogen yield for a $5 \mathrm{~A}$ stored beam is 250 molecules on $\mathrm{s}^{-1}\left(3 \times 10^{-6}\right.$ monolayer per year if all of the released hydrogen should condense). The actual yield probably will be even less, because such a slow proton would lose most of its energy to excitation of orbital electrons $r$ ather than ionization of the water molecules. 11 since the G-values of the hydrocarbons and water are comparable, a similar conclusion can be drawn for hydrocarbons. therefore expect no significant release of hyciroyen from ion bombardment.

\section{Mechanical Design of the Cold-Bore Region}

In this region; care must be taken to avoid hel ium leaks into the ultrahigh vacuum system. As shown in Fig. l, the bore tube in each magnet is a thick monol ithic structure which extends suff iciently far into the transition region between magnets that there is no weld between the helium region and the inner vacuum systen. For helium to leak into thr: ultrahigh vacuum, it must either penetrate thr: integral seamless aluminum structure or go throuxhl (w) welds separated by the insulating vacuum.

Since the insulating vacuun will be cryopumped by some $300 \mathrm{~cm}^{2}$ of cryosorption material in each transition region, it is extremely unlikely that significant amounts of helium (or other gases) will penetrate into the ultrahigh vacuum.

Between magnets the inner tube containing the ultrahigh vacuum is formed by a stainless-steel tube and stainless-steel bellows, welded at each end to an Al-ss bonded transition piece. It contains a bellows shield to reduce the impedance seen by the tream, a ceramic insert for the clearing electrodes, and a welded can containing a baffled titanium subl imat. ion pump. This unit will be prefabricated, then leak checked and temperature cycled between $150^{\circ} \mathrm{C}$ and $4.5^{\circ}$. Only one aluminum weld per magnet will be required on the inner tube curing field assembly.

A heat shield at $90 \%$ surrounds the outer vacuum so that between magnets the region both inside as well as outside the inner tube will be cryopumped. At $4.5 \%$, there should be a completely negligible leak rate from outer to inner system through any component of the inner tube. Standard commercial components for the ultrahigh vacuum appl ications have guoted leak rates of less than $10^{-10}$ standard $\mathrm{cm}^{3} / \mathrm{s}$. The Al-ss transition pieces and the all-welded nature of the inner vacuum vessel should have leak rates no worse than this. Since we will operate the outer vacuum at a room-temperature pressure of $10^{-5}$ Torr, this gives a 
leak rate of $10^{-15} \mathrm{Torr}-\mathrm{D} / \mathrm{s}$. Evon if the 6 welds ano Al-SS transition pleces were to each leak at this rate, would still have a total leak of only $6 \times 10^{-15}$ Turr- $1 / 5$ in each transition region. This amounts to less than $10^{-2}$ monolayer per year.

Since all components will be leak checked over several temperature cycles before installation, the possibility of troublesome leaks developing is minimal. Test assenhlies will he used to opt imize the welding technikur in order to minimize the porsitility of loakci frem the acuminum weld maxes in thes field.

11 Iroks: do in.veless, they will ar ditticult to

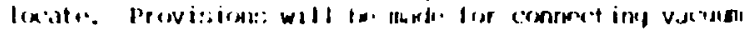

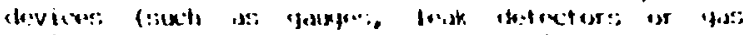

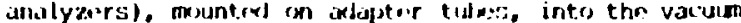
system at the baso of thr titanium pump housing. After evacuation and the completion of tests. the adopter tures can te severed and sealed off with a pinch-oft tool, and the vacuum devices renoved trom the system without opening the bore tube to the atmosphere.

\section{Warm-to-Cold Transition and Interaction Region}

To prevent significant molecular streaming from the $10^{-11}$ Torr warm-bore straight-section region into the cold-bore curved region, a cryosorption puming section will be placed between the warm sector valve and the cold bore. A Monte Carlo studyl2 of the transmissivity of a cylindrical pipe indicates that for a 6-cm ID bore tube and a stick ing coefficient of U.b, a 70-cm pumping region will reduce transmission by a factor of $4 \times 10^{-3}$ for an initial uniform yas distribytion. For a cosine distribution, this becomeg $6 \times 10^{-3}$. The tubular condensation cryopump developed at CHPN has a $70-\mathrm{cm}$ pumping length and a $l$ imiting pressure in the $10^{-14}$ Torr range. It appears to be eminently suitable for our application, but if additional reduction in the transmission is required, a longer cryopum can be used. As an extreme example, a 6-m pumping region should reduce the transmission by another two orders of magnitude.

On the warm-bore side of the cryopump will be a sector valve, the roughing and turbo-molecular punps, a second sector valve, and a fast-acting flapper valve capable of closing within $20 \mathrm{~ms}$ after a vacuum failure. The cold connections will be welded, while those at room temperature will be flanged. The warmbore regions will be maintained at $10^{-11}$ Torr by pumping stations every $5 \mathrm{~m}$.

\section{Punpdown Procedure}

Leak checking and assembly will proceed one sector (one-twelfth of the $r$ ings) at a time. After assenbly, the sector will be roughed down to $10^{-3}$ Torr with the roughing and turbo-molecular pumps at each end. The insulating vacuum system surrounding the inner bore tube will also be roughed down. For

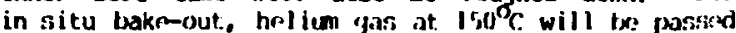
through the manget siystrem in placre of thw: usual 1 iquid helium. Pumping till conitinue from the ends during this time, and as the pressure near the pumps drops to the $10^{-5}$ Tor $r$ level, the closest subl imation pump will be activated. As the pressure drops along the length of the sector, succeeding punps will be turned on and the pressure will drop to $10^{-7}$ Torr. Then the heat source will be turned off and cooldown to room temperature will occur. The anticipated outgassing $r$ ate is $4 \times 10^{-14}$ Torr $\ell^{-2} \mathrm{sec}^{-1}$ at roan temperature. Cooldown to $4.5 \% \mathrm{~g}$ could then start, The total residual gas load at $10^{-9}$ Torr is only $10^{-6}$ monolayers. As cooldown to $4.5 \%$ starts, the outgassing rate becomes smaller and teromes essentially zero at $4.5 \%$.

\section{References}

1. R. C. Wolgast, IEEE Trans. Nucl. Sci, NS-22, 1446 (1975). We would like to thank N. Milieren and R. wolgast of Lawrence Berkeley Laboratory fror the ir valuable comments and criticism.

2. G. Moraw and R. Dobrozmsky, Proc. bth int. Vacuum Congr. 1474, Japan; J. Afpll. Phys. S(d)pl. 2. Pt. 1. 1974.

3. ii. .1. Halama and .1. C. Horrará, I. Var. :ir.l. Irati. 13, 46, (19\%).

4. H. :3. Colibe, (YHN/ISile-ns/74-1) (19/4).

3. C. Bsenvenuti, Frormilat, $-74 /$ Juy (1974).

6. H. J. Herrara, I IEEt Trans. Nucl. Sci. NS-22, 1442 (1975).

7. E. Fischer and K. Zankel, CEFN-ISR-VA $7:-1,2$ (1973); O. Grobner and R. S. Calcier, IEEE Trans. Nucl. Sci. NS-20, 760 (1973).

8. We use the hydrogen ionization crosssection $=2.1 \times 10^{-19} \mathrm{~cm}^{2} /$ atom and the stickir.g coefficient $x 1.0$.

9. S. K. Erents and G. M. Mccracken, Proc. 6th Symp. on Fusion Technology. Aachen, 1972, p. 161. S. K. Erents and G. M. MoCracken, J. Appl. Phys. 44. 3139 (1973). $\quad$ S. K. Erents and G. M. Mocracken, Proc. 5th International Conference on Collisions Sol ids, Gatl inturg, Tenn.. 1973.

10. J. A. Ghormley and D. C. Stewart, J. Am. Chrm. Soc. 78, 2934 (1956). J. A. Thomas, Advaners in Radiation Chem. 1. 103 (1969).

11. M. S. Matheson, Chem. Division, privat. Commun icat ions.

12. D. Blechschmidt, J. Vac, Sci. Technol. 11, i,70 (1974).

13. C. Benvenut $i$ and $D$. Blechschnidt, CEFN Internal Report CERN-ISR-VA74/4.

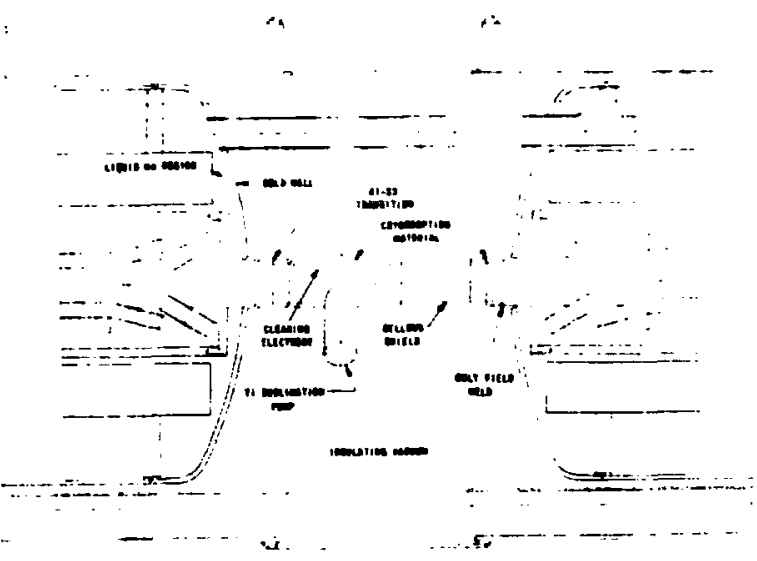

Fig. I Cold-bore transition assembly between magnets. 